\title{
Landscape ecology meets landscape science
}

\section{Journal Article}

Author(s):

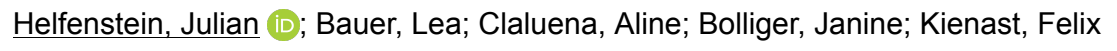

Publication date:

2014-08

Permanent link:

https://doi.org/10.3929/ethz-b-000088117

Rights / license:

In Copyright - Non-Commercial Use Permitted

Originally published in:

Landscape Ecology 29(7), https://doi.org/10.1007/s10980-014-0055-6 


\title{
Landscape ecology meets landscape science
}

\author{
Julian Helfenstein • Lea Bauer • Aline Clalüna • \\ Janine Bolliger $\cdot$ Felix Kienast
}

Received: 19 March 2014 / Accepted: 10 June 2014/Published online: 27 June 2014

(C) Springer Science+Business Media Dordrecht 2014

\begin{abstract}
Landscape ecology is a broad field in a patchwork of related disciplines. Giving landscape ecology a definition and delimiting it from related research areas is both a challenge and a necessity. Past endeavors have focused on expert opinions, analyses of published papers, and conference proceedings. We used a mix of all three, including a unique keyword analysis in two leading landscape-related journals, to highlight latest developments in landscape ecology between 2010 and 2013. Our analysis confirms the key topics of $\mathrm{Wu}$ (Landscape Ecol 28(1):1-11,2013), and suggests that of those connectivity is dominating in terms of research output. However, we also found evidence that the borders of the journal Landscape Ecology are fuzzier than sketched in recent publications. There is a large overlap with the journal Landscape and Urban Planning, and in general a growing weight of conservation, landscape management, and planning related issues in the landscape ecology community. We conclude by encouraging the continued inclusion and strengthening of socio-
\end{abstract}

J. Helfenstein $(\square) \cdot$ L. Bauer · A. Clalüna Institute of Terrestrial Ecosystems, Swiss Federal Institute of Technology (ETH) Zurich, Universitätsstrasse 16, 8006 Zürich, Switzerland e-mail: helfenstein40@ hotmail.com; julianh@student.ethz.ch

\section{J. Bolliger · F. Kienast}

Swiss Federal Institute for Forest, Snow and Landscape Research WSL, Zuercherstrasse 111, 8903 Birmensdorf, Switzerland ecological hot topics such as urban studies and landscape-human interactions in landscape ecological studies and subsequently in the journal landscape ecology.

Keywords Landscape ecology - Core questions · Key topics · Future direction · Connectivity · Urban studies $\cdot$ Planning $\cdot$ Management

\section{Aim of this perspective}

Landscape ecology is by definition a socio-ecological science (Risser et al. 1984). As part of the umbrella field "landscape science" (Kienast et al. 2007; Wu 2013), landscape ecology shares the notion of landscape with other subjects such as landscape planning and landscape architecture, conservation as well as urban sciences (Risser and Iverson 2013). To define the boundaries of the field, many authors have outlined landscape ecology based on expert assessments as well as key research areas covered in the journal landscape ecology (Wiens 1992; Forman 1995; Hobbs 1997; Antrop 2001; Wu and Hobbs 2002; Wu 2013). Some authors (e.g. McIntyre et al. 2013) have used conference reports to derive hot topics of the field. In order to confirm or redefine the hot topics presented by $\mathrm{Wu}$ (2013), we repeated some of the above-mentioned analyses by performing keyword analysis for the years 2010-2013 and by screening conference reports of major International Association for Landscape Ecology (IALE) conferences held in 
Table 1 Top 30 most frequent keywords in papers published in Landscape Ecology and Landscape and Urban Planning from 2010 to 2013

\begin{tabular}{|c|c|c|c|}
\hline \multicolumn{2}{|c|}{ Landscape Ecology } & \multicolumn{2}{|c|}{ Landscape and Urban Planning } \\
\hline Keyword & Frequency & Keyword & Frequency \\
\hline connectivity & 29 & urbaniz(s)ation & 60 \\
\hline fragmentation & 29 & GIS & 43 \\
\hline dispersal & 24 & urban ecology & 24 \\
\hline climate change & 22 & biodiversity & 21 \\
\hline habitat fragmentation & 22 & ecosystem services & 21 \\
\hline biodiversity & 16 & land use & 21 \\
\hline conservation & 16 & urban planning & 16 \\
\hline landscape structure & 16 & climate change & 14 \\
\hline scale & 16 & landscape change & 14 \\
\hline graph theory & 15 & remote sensing & 14 \\
\hline land use & 14 & green space & 13 \\
\hline remote sensing & 14 & landscape metrics & 12 \\
\hline ecosystem services & 13 & land use planning & 11 \\
\hline landscape & 13 & landscape planning & 11 \\
\hline landscape genetics & 13 & fragmentation & 10 \\
\hline urbanization & 13 & land use change & 10 \\
\hline spatial scale & 12 & landscape & 10 \\
\hline functional connectivity & 11 & landscape ecology & 10 \\
\hline landscape ecology & 11 & green infrastructure & 9 \\
\hline landscape metrics & 10 & sustainability & 9 \\
\hline metapopulation & 10 & urban forest & 9 \\
\hline spatial heterogeneity & 10 & urban forestry & 9 \\
\hline heterogeneity & 9 & urban green space & 9 \\
\hline land cover & 9 & urban growth & 9 \\
\hline landscape pattern & 9 & China & 8 \\
\hline agriculture & 8 & connectivity & 8 \\
\hline gene flow & 8 & conservation & 8 \\
\hline GIS & 8 & conservation planning & 8 \\
\hline historical ecology & 8 & land cover & 8 \\
\hline landscape configuration & 8 & protected areas & 8 \\
\hline
\end{tabular}

Bold lettering of keywords in Landscape Ecology means the keywords pertain to connectivity; faded out keywords in Landscape and Urban Planning do not overlap with the top 30 keywords from Landscape Ecology

2007, 2011, and 2013. Since innovation in a field frequently happens at its boundaries, we did not only analyze all keywords from published papers in Landscape Ecology, but also those from the journal Landscape and Urban Planning. The latter is an important journal for the landscape planning community.

\section{Hot topics in landscape ecology confirmed}

The core topics of landscape ecology, that also largely determine what is published in the journal Landscape Ecology, were defined by Wu (2013) to be:
1. "Pattern-process-scale relationships of landscapes,

2. Landscape connectivity and fragmentation,

3. Scale and scaling,

4. Spatial analysis and landscape modeling,

5. Land use and land cover change,

6. Landscape history and legacy effects,

7. Landscape and climate change interactions,

8. Ecosystem services in changing landscapes,

9. Landscape sustainability,

10. Accuracy assessment and uncertainty analysis" (Wu 2013).

Our keyword analysis confirms that these topics are indeed the dominant topics in the journal, also between 2010 and 2013. Among the top thirty most frequent keywords from 2010 to 2013, there is at least one keyword that pertains to each topic, except for topic 10 "accuracy assessment and uncertainty analysis" (Table 1). However-and this is a general constraint to keyword analyses-this does not necessarily mean that the topic is not widely present in landscape ecological studies. Authors may simply be less likely to use words relating to accuracy assessment and uncertainty analysis as keywords in their articles. Despite these methodological limitations, the obvious links between the most frequent keywords and Wu's core topics provides further support for the main research areas and their use as indicators for what is being published in landscape ecology's flagship journal.

\section{The triumph of connectivity}

While the ten core topics of landscape ecology are reflected in the most frequent keywords, the distribution is far from equitable. Connectivity, which was not yet considered a core topic of landscape ecology in 2001 by $\mathrm{Wu}$ and Hobbs (2002), clearly dominates in terms of keyword frequencies today. "Connectivity" and its siblings "fragmentation", "dispersal", and "habitat fragmentation" occupy four of the top six positions in the frequency analysis and highlight the strong conservation background of the landscapeecology community (Table 1). The success of this field may be due to its applicability in management, the bond with network analysis, and the rise of landscape genetics. 
While connectivity is mostly important for conservation, where it may be used to assess habitats in the perception of the species of interest (e.g. Kool et al. 2013), it is also an effective method to evaluate and model the spread of invasive species (e.g. Vilà and Ibáñez 2011). The bond with network and least-cost analysis opened a valuable toolkit, making fragmentation quantifiable. Furthermore, the development of user-friendly software to calculate landscape connectivity, such as Conefor Sensinode (e.g. Saura and Torne 2009) or Circuitscape (e.g. McRae et al. 2008), together with numerous connectivity indices (Laita et al. 2011; Fragstats: McGarigal 2012; GUIDOS: Vogt 2012), has led to an exponential increase of graph-theoretic connectivity applications (Moilanen 2011).

The use of genetic markers in landscape genetics has allowed connectivity analysis to be more organism-focused, as opposed to strictly concentrating on landscape structure-a further boost to connectivity research (Storfer and Murphy 2010). First explicitly mentioned in ISI papers only in the early 2000s, landscape genetics is now a major field (Holderegger and Wagner 2006). In 2006 it was the topic of a special issue in Landscape Ecology, today it is one of the most frequent keywords in publications, with further growth seemingly imminent (Bolliger et al. 2014).

\section{Not just scale, pattern and processes}

Despite the prevalence of certain topics, our results indicate that landscape ecology is a very broad field, broader than suggested in recent publications. Keyword frequencies show a strong exponential decay; from the 3,137 keywords analyzed, $83 \%$ of all keywords occur only once, and an additional $9.7 \%$ occur only twice (Fig. 1). According to these keywords, landscape ecology reaches far beyond the classical themes "scale", "spatial heterogeneity", and "pattern and processes", which should-according to $\mathrm{Wu}$ (2006, 2013)—account for over $50 \%$ of the papers. Our analysis cannot confirm this prevalence of the classical themes, at least not at the magnitude reported by $\mathrm{Wu}(2006,2013)$. Only $1.1 \%$ of the over 3,000 keywords contained the word or word fragment "heterogeneity", $3.2 \%$ "spatial", $1.8 \%$ "scale", $1.2 \%$ "pattern", $0.1 \%$ "process." Words or word fragments of non-classical topics such as

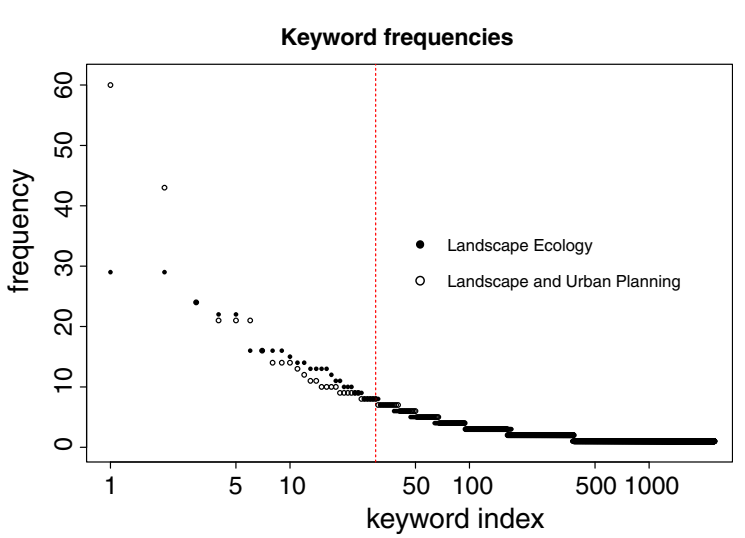

Fig. 1 Exponential decline of keyword frequencies from the journals Landscape Ecology and Landscape and Urban Planning. $83 \%$, respectively $84 \%$ of the keywords occur only once (note the log-scale of the $x$-axis). The top thirty most frequent keywords are to the left of the dotted line

“connectivity" (1.8\%), “fragmentation" (2.1\%), "climate" (1.1\%), "forest" (2.7\%), "urbanization" $(2.6 \%)$, “diversity" $(1.7 \%)$, agriculture $(1.0 \%)$, or conservation $(1.0 \%)$ seem to be equally important. Many of these "non-classicals" are the clear winners if overlaps with other important landscape science communities are considered, e.g. overlaps with the landscape planning or the conservation community, both offering great potential for synergies and innovations.

\section{The bridge to landscape planning}

Fourteen out of the top 30 most frequent keywords found in Landscape Ecology are also in the top 30 for Landscape and Urban Planning (Table 1). The distribution of keywords is also structurally very similar (Fig. 1). The overlap of key topics confirms the broad range of topics covered by the landscape science community and highlights important emerging topics, where landscape ecologists, conservation managers, and landscape planners could play an important role in solving pressing environmental issues. This includes the fast growing field of landscape and urban design. Urban design increasingly includes the design of environmentally sound green corridors and infrastructure (e.g. roofs, sidewalk strips, vertical gardens, parks, restored streams, etc.) for biodiversity, connectivity, ecosystem services, and human well-being. 


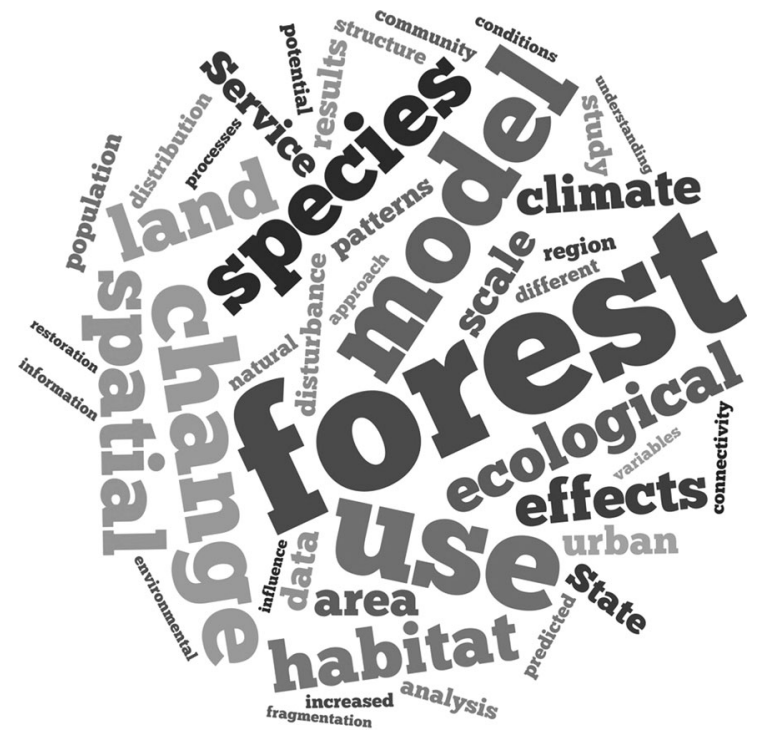

Fig. 2 Word cloud from the IALE congress in Portland, USA. The congress was held from April 3rd-7th, 2011

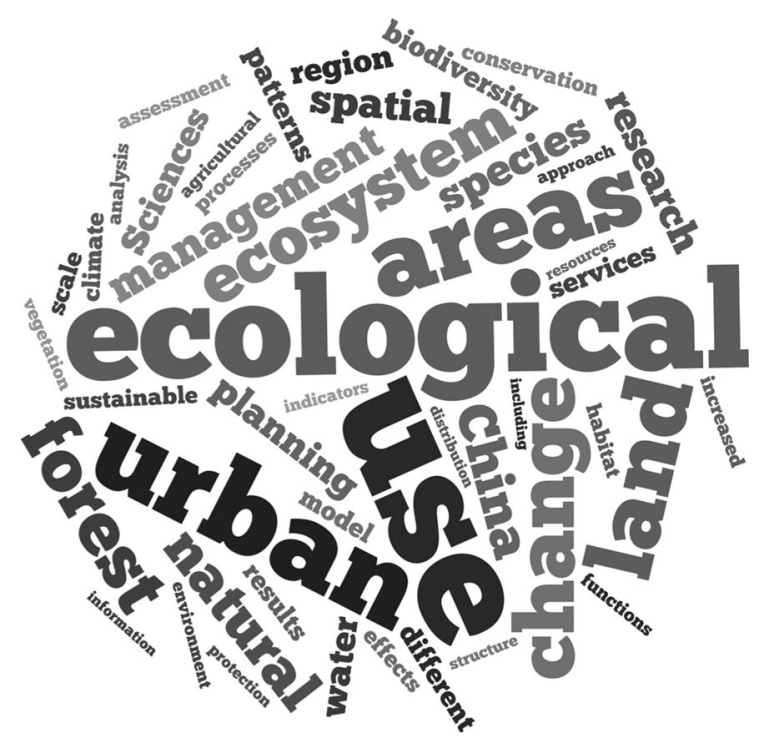

Fig. 3 Word cloud from the IALE world congress in Beijing, China from August 18th-23rd, 2011. Note the important role of the word "urban" and the appearance of the word "planning". These words either do not show up at all or much smaller in the US-IALE congress

Recent conferences of the IALE provide further evidence for the overlap with landscape planning. We screened the abstracts and keynotes of four major IALE congresses since 2007: the IALE world conferences in Wageningen (2007) and Bejing (2011), as well as the two regional IALE conferences in Portland (2011) and Manchester (2013). Two selected word clouds, one from the US-IALE conference in Portland, USA and one from the world congress in Beijing, China (Figs. 2, 3) highlight the two pillars of current research activity in landscape ecology. Socio-ecological aspects, especially "urban", were more prevalent at the conference held in China, whereas more purely ecological aspects were more strongly represented at the conference in the USA. Active collaboration and true interdisciplinarity between these poles would be a logical future development of the field landscape ecology. And major steps in this direction have already been taken. The rise of connectivity at the landscape scale, the adoption of the design paradigm (Nassauer and Opdam 2008), and an increasing focus on people-landscape interactions with a strong participatory component, already represents the leaving of the "pattern and processes" paradigm for more management and planning related issues.

Interestingly, connectivity related words only appear very small ("connectivity" and "fragmentation" in the US-IALE word cloud), which somewhat relativizes the dominant position connectivity has in keyword frequencies of published articles in the journal landscape ecology. Due to the fundamentally different methodology (comparing all non-fill words versus only considering keywords), it is not surprising that the word clouds are different from the results of the keyword analysis. However, when considering both of these results, one can still draw some interesting conclusions.

\section{Conclusion}

Our update of dominant and emerging topics in Landscape Ecology coincide mostly with the core areas defined by $\mathrm{Wu}$ (2013). Although the classical themes such as pattern, processes, scale and spatial heterogeneity are clearly visible, we can no longer confirm the prevalence of these topics. Rather, it seems that the landscape ecology community's research foci have shifted, as we detected several equally important, emerging thematic poles. They primarily encompass themes related to connectivity and conservation at the landscape scale, landscape design, urban studies, and people-landscape interactions such as climate change and ecosystem services. 
According to keyword frequencies, the purely ecological and conservation-related topic of connectivity is presently the most prolific topic in the journal, while more socio-ecological aspects dominate the neighboring journal Landscape and Urban Planning. If the landscape ecology community wants to represent the large community of landscape ecologists, especially the growing weight of the urban research community, it should strengthen the focus on socio-ecological research areas and urban issues.

Landscape ecology as an inherently interdisciplinary field is extremely broad-analysis of scale and heterogeneity is only one topic among many. But this broadness should be cherished and not constrained. The resilience that comes with broadness may prove to be key for the continued success of landscape ecology. It is the diversity of tools and methods, together with an interdisciplinary approach, that will guarantee that landscape ecology can adapt to changing interests and needs for understanding the dynamics, structures and processes of landscapes in the future. A lot of this change will occur in urban areas. Already more than half of the world's population lives in cities (The World Bank 2012). Studying land-use problems, ecosystem service trade-offs, landscape-scale connectivity and conservation, and spatial effects of climate change on urban environments is already a main field in landscape ecology and will become even more important in the future. To guarantee the future success of landscape ecology, it is important to continue to be broad and practical, and to strengthen the focus on socio-ecological systems, including urban environments.

Acknowledgments All analyses and calculations were done using the statistical program $R$ (R Core Team 2013). The word clouds were made with Tagxedo, $<$ http://www.tagxedo.com/> (Accessed March 17, 2014). We would like to thank Jianguo Wu and two anonymous reviewers for insightful comments and suggestions.

\section{References}

Antrop M (2001) The language of landscape ecologists and planners a comparative content analysis of concepts used in landscape ecology. Landsc Urban Plan 55(3):163-173

Bolliger J, Lander T, Balkenhol N (2014) Landscape genetics since 2003: status, challenges and future directions. Landscape Ecol 29(3):361-366

Forman R (1995) Some general principles of landscape and regional ecology. Landscape Ecol 10(3):133-142

Hobbs R (1997) Future landscapes and the future of landscape ecology. Landsc Urban Plan 37(1-2):1-9
Holderegger R, Wagner H (2006) A brief guide to landscape genetics. Landscape Ecol 21(6):793-796

Kienast F, Gosh S, Wildi O (eds) (2007) A changing world: challenges for landscape research. landscape series. Springer, Dordrecht

Kool JT, Moilanen A, Treml EA (2013) Population connectivity: recent advances and new perspectives. Landscape Ecol 28(2):165-185

Laita A, Kotiaho JS, Mönkkönen M (2011) Graph-theoretic connectivity measures: what do they tell us about connectivity? Landscape Ecol 26(7):951-967

McGarigal K, Cushman SA, Ene E (2012) FRAGSTATS v4: spatial pattern analysis program for categorical and continuous maps. computer software program produced by the authors at the University of Massachusetts, Amherst

McIntyre NE, Iverson LR, Turner MG (2013) A 27-year perspective on landscape ecology from the US-IALE annual meeting. Landscape Ecol 28(10):1845-1848

McRae BH, Dickson BG, Keitt TH, Shah VB (2008) Using circuit theory to model connectivity in ecology, evolution and conservation. Ecology 89(10):2712-2724

Moilanen A (2011) On the limitations of graph-theoretic connectivity in spatial ecology and conservation. J Appl Ecol 48(6): 1543-1547

Nassauer JI, Opdam P (2008) Design in science: extending the landscape ecology paradigm. Landscape Ecol 23(6):633644

R Core Team (2013) R: A language and environment for statistical computing. R foundation for statistical computing, Vienna, Austria. http://www.R-project.org/ Accessed 20 Jan 2014

Risser PG, Iverson LR (2013) 30 Years later-landscape ecology: directions and approaches. Landscape Ecol 28(3): 367-369

Risser P, Karr J, Forman R (1984) Landscape ecology: directions and approaches, Illinois Natural History Survey Special Publ. 2, Champaign, Illinois

Saura S, Torne J (2009) Conefor Sensinode 2.2: a software package for quantifying the importance of habitat patches for landscape connectivity. Environ Model Softw 24(1): 135-139

Storfer A, Murphy M (2010) Landscape genetics: where are we now? Mol Ecol 19(17):3496-3514

The World Bank (2012) Urban development data. http://data. worldbank.org/topic/urban-development. Accessed $27 \mathrm{Feb}$ 2014

Vilà M, Ibáñez I (2011) Plant invasions in the landscape. Landscape Ecol 26(4):461-472

Vogt P (2012) User guide for GUIDOS, European Commission Joint Research Center

Wiens J (1992) What is landscape ecology, really? Landscape Ecol 7(3):149-150

Wu J (2006) Landscape ecology, cross-disciplinarity, and sustainability science. Landscape Ecol 21(1):1-4

Wu J (2013) Key concepts and research topics in landscape ecology revisited: 30 years after the Allerton Park workshop. Landscape Ecol 28(1):1-11

Wu J, Hobbs R (2002) Key issues and research priorities in landscape ecology: an idiosyncratic synthesis. Landscape Ecol 17(4):355-365 